This item was submitted to Loughborough's Research Repository by the author.

Items in Figshare are protected by copyright, with all rights reserved, unless otherwise indicated.

\title{
Robotic disassembly for increased recovery of strategically important materials from electrical vehicles
}

\section{PLEASE CITE THE PUBLISHED VERSION}

https://doi.org/10.1016/j.rcim.2017.09.013

\section{PUBLISHER}

(c) Elsevier

\section{VERSION}

AM (Accepted Manuscript)

\section{PUBLISHER STATEMENT}

This work is made available according to the conditions of the Creative Commons Attribution-NonCommercialNoDerivatives 4.0 International (CC BY-NC-ND 4.0) licence. Full details of this licence are available at: https://creativecommons.org/licenses/by-nc-nd/4.0/

\section{LICENCE}

CC BY-NC-ND 4.0

\section{REPOSITORY RECORD}

Li, Jie, Michael Barwood, and Shahin Rahimifard. 2017. "Robotic Disassembly for Increased Recovery of Strategically Important Materials from Electrical Vehicles". Loughborough University. https://hdl.handle.net/2134/27441. 


\title{
Robotic disassembly for increased recovery of strategically important materials from electrical vehicles
}

\author{
J. Li, M. Barwood and S. Rahimifard \\ Centre for Sustainable Manufacturing and Recycling Technologies (SMART), Loughborough University, UK
}

\begin{abstract}
The rapid growth of market share of Electrical Vehicles (EVs) and their increasing amount of electric and electronic components have introduced difficult challenges for future recycling of such vehicles. End of Life Vehicles (ELVs), together with Waste from Electric and Electronic Equipment (WEEE), are renowned as an important source of secondary raw materials. In addition, a significant proportion of the hidden value at the End-of-Life (EoL) of the EVs is embedded in the light fractions containing complex material mixtures, i.e. the management of electronic components that has been rarely considered in the scientific literature. The purpose of this paper is to fill this gap through the use of an innovative disassembly approach to identify the profitability of recycling such electronic components. The novel approach, based on the utilisation of a robotic system, disassembles and extracts Strategically Important Materials (SIMs) from EV components, thereby improving the concentration of these materials prior to final recycling and refining processes. This paper presents the challenges in the robotic disassembly of Electrical and Electronic (E\&E) components. A case study has also been included to demonstrate that an average $95 \%$ of the materials and their associated recovery value could be achieved.
\end{abstract}

Keywords: Recycling, Electric Vehicle, Robotic Disassembly, Automotive Electronic Component

\section{Introduction}

The rapid growth in the number of traditional vehicles with internal combustion engines has increased the demands for fossil fuel and exacerbated their environmental impacts [1,2]. Driven by government incentives and customer desire for more fuel-efficiency and cleaner forms of transportation, an ever-increasing number of alternative fuel vehicles have been introduced to the global automobile market, ranging from natural gas, fuel-cell and hybrid electric to fully electric vehicles (Figure 1) [3]. The use of such alternative fuel vehicles is thought to be a vital part of future sustainable transportation policies; thus, it is predicted that the production of these vehicles is set to further increase. Both the volume and the content of the waste generated by the automotive section however make ELVs one of the most significant sources of EoL products [4]. The total number of ELVs in the EU-27 was 9 million in 2009 and in the UK is 2 million in 2014 [5, 6]. It is predicted that the generation of waste ELVs will be 19.5 million tons in 2020 [7, 8].

It is noted that one of the key differences in the design of EVs is the significantly larger number of E\&E components that involve the management of almost all functionalities of the vehicles [9]. Therefore, this trend would lead to an increase in the production of Printed Circuit Boards (PCBs) and the generation of waste PCBs that need to be recycled and recovered. Additionally, an increasing range of materials is required as part of these electronic devices, often referred to as SIMs, i.e. Precious Metals (PMs) and Rare Earth Elements (REEs).

On average of all traditional and alternative fuel vehicles $15 \mathrm{E} \& \mathrm{E}$ components are embedded in a modern standard medium-sized car but this number can rise to 48 in a luxury car, including microcomputers and Electronic Control Unit (ECUs) [10-12]. They are used to read and process signals from various sensors, to control the performance of the sub-systems, such as engine, air-bag and airconditioning systems [13]. It is also estimated that the value of the automotive electronic components can account for $30 \%$ to $50 \%$ of the cost of some vehicles [12]. The automotive electronic components can be seen as a special type of e-waste whose majority of their environmental impacts is caused by the recycling of PCB. It consists of complicated materials, including heavy metals, e.g. lead, chromium, cadmium; toxic substances e.g. brominated flame retardants; and valuable materials e.g. gold, silver and palladium [14].

Current EoL treatment for automotive ECUs is non-existent, and they are simply left within ELVs which are sent for shredding and material recovery. However, this inappropriate recycling method results in a serious environmental impact arising from the discarding of hazardous materials, and poor economic performance due to the loss of the valuable materials that are in small quantities, i.e. SIMs. This evidence highlights the importance of recovery of these automotive electronic components in regards to both the embedded value and environmental aspects.

Given the national and international legislative requirements the global ELV recycling industry has been established in different countries. Direct management systems have been designed and developed in the European countries, China, Japan and Korea. The EUDirective 2000/53/EC on ELVs was introduced with specific recycling and recovery targets. EU Member States, e.g. Denmark, Netherlands, Belgium, Finland have established detailed rules on compliance with this Directive in different ways [15]. In China, the ELV recycling regulations enacted in 2001 with the introduction of an ELV collection system [15]. The Law for ELV recycling was enacted in Japan in 2005 to promote the reduction of Automotive Shredder Residue (ASR) [16]. Furthermore, the action for Resource Recycling of Electrical and Electronic Equipment and Vehicles has been enforced in Korea in 2008 [17]. Additionally, driven by market mechanism, an indirect management system has been built for ELVs in the US. Current vehicle recycling activities are

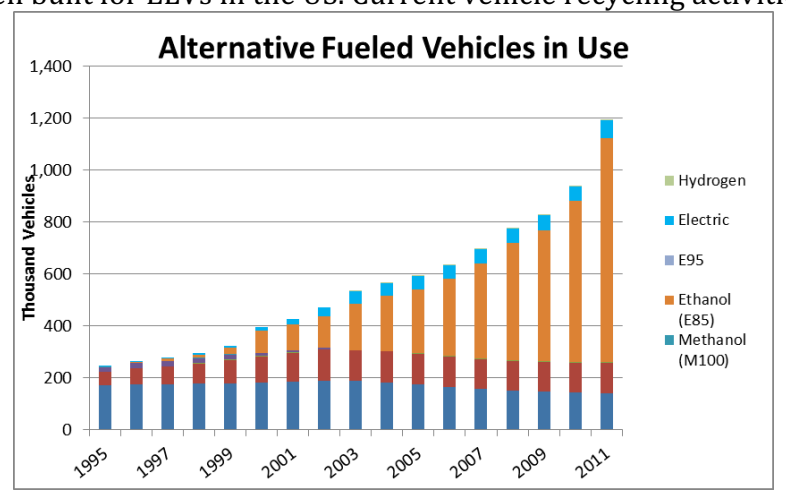

Figure.1 Growth of alternative fuel vehicles models [3]. 
predominantly based on automated fragmentation and separation processes which are designed for recovering basic metallic contents (e.g. steel, aluminium and copper) that often represent a significant proportion of weight ( $>70 \%)$ of traditional vehicles [18]. Increased amount of advanced and lightweight materials has been used in modern vehicles to improve the fuel economy and maintain the safety and performance, such as high-strength steel, aluminium alloys, carbon fibre and polymer composites [19]. It is evident that vehicle material composition has moved away from metals and transitioned more toward lighter materials.

In comparison, although SIMs content presents a substantial proportion of the hidden value contained in modern vehicles, it often represents a much smaller proportion of the weight of vehicles $(<5 \%)$ [10]. It has also been identified that the research on the EoL management of the scrap automotive electronic (i.e. ECUs) is very limited [20].

The potential for developing an appropriate recycling approach for the automotive electronic components contained in EVs has been identified in this research. The recycling approach should be able to liberate and extract sensitive and valuable materials i.e. SIMs, from these components. Thus, this paper highlights a need for the development of bespoke EoL management technologies and processes tailored to the specific requirement of EVs.

In this context, a number of researchers have investigated a range of automated approaches for disassembly and improved concentration of valuable materials, prior to final recycling and refining processes. Michalos et al., [21] discussed the application and benefits of robotic technologies in automotive assembly. Duflou et al. [22] have reviewed various disassembly practices and highlighted the importance of automation techniques as well as tooling and fixturing systems for achieving flexibility and robustness of disassembly processes. In relation to this, a number of research projects have proposed the use of robotic systems in disassembly of electronic products. Knoth et al. [23] have developed an intelligent robotic disassembly process which utilised a vision system to identify components for extraction, and was capable of removing components based on a series of simple robotic processes. Basdere and Seliger [24] have explored the use of robots within a flexible disassembly and recovery line for large and small size electrical consumer goods. Vongbunyong et al. [25] have also proposed the concept of "cognitive robotic system" for disassembly of LCD screens and TVs, utilising a vision system, and have highlighted further flexibility and configurability challenges to deal with multi-product designs. In Korea, a smart dismantling monitor and trolley system has been developed to facilitate remote real-time monitoring of the dismantling status in each workstation [17]. Wegener et al. [26] have focused on disassembly of the batteries in hybrid cars and have proposed as their future work, investigation into the use of robots in this application. Wegener et al. [27] have also presented a concept of hybrid human robot disassembly workstations for EV battery disassembly, in which the assisted robot performs simple and repetitive tasks using provided location information. Pintzos et al., [28] proposed an approach for generating relevant disassembly information based on design files for disassembly line planning. Radaschin et al., [29] presented a concept of a product-driven control to cope with the disassembly object variety, different product conditions and amounts. In terms of the estimation of recyclability, Papakostast al., [30] developed a computer-aided design assessment which enables designers and engineers understand the recyclability of the designs in the first phase of the EoL management. Feldmann et al. [31] touched upon the issue of disassembly costs and highlighted the difference in recycling costs and benefits between various materials fractions.

The research reported in this paper aims to build upon the existing work in this area and to specifically address the flexibility and reconfigurability challenges in dealing with a varying size of components from EVs. The paper is structured as follows; section 2 of the paper provides a brief review of relevant literature and an overview of current vehicle recycling and recovery practices. Section 3 presents a framework for assessing EoL requirements for EV components, and describes a robotic disassembly approach for recycling of components within EVs in order to maximise the value recovery and minimise the environmental impacts. The applicability of the framework is demonstrated in section 4, the case study. Finally, Section 5 presents concluding remarks and future perspectives.

\section{EoL vehicle recycling}

\subsection{Overview of EoL vehicle recycling}

Due to financial incentives and legislative requirement in relation to the ELV Directive, there has been a significant investment and improvement in vehicle recycling systems. Although the exact processes may vary marginally in various countries, a typical flow diagram of the current recycling and recovery route for ELVs is illustrated in Figure 2.

ELVs are collected and transported to an authorised treatment centre. The first stage is the de-pollution that removes battery, fluids, lubricants, tires and other hazardous substances. Easily accessible, valuable parts are dismantled manually for reuse or remanufacturing. Then the hulks are pressed and sent to the shredding centre. In the shredding process, the hulks and other material scraps that may come from consumer goods (such as white goods) are processed together. The shredders use huge hammers to crush hulks into pieces within a drum. After the shredding process, materials are sorted and separated into different groups, such as ferrous, nonferrous metals and shredder residue [32]. The initial process is the magnetic separation for liberating ferrous (all iron and steel, except stainless steel) from non-ferrous materials (which may include both metals and non-metals). The subsequent operation is to separate remaining non-ferrous metals from non-metallic materials, referred to as light Auto Shredder Residues (ASRs) through eddy current separation, air separation and/or dense media separation. In the group of non-ferrous metals, aluminium and steel can be separated by "light media" and "heavy media" properties [33]. Copper and brass are separated using additional "image processing" approaches. The rest of the materials such as plastic, glass, paper, wood, fabric, rubber, and urethane foam are further processed to liberate and recycle these materials. The remaining material that cannot be separated is sent for energy recovery or to landfill as ASR. 


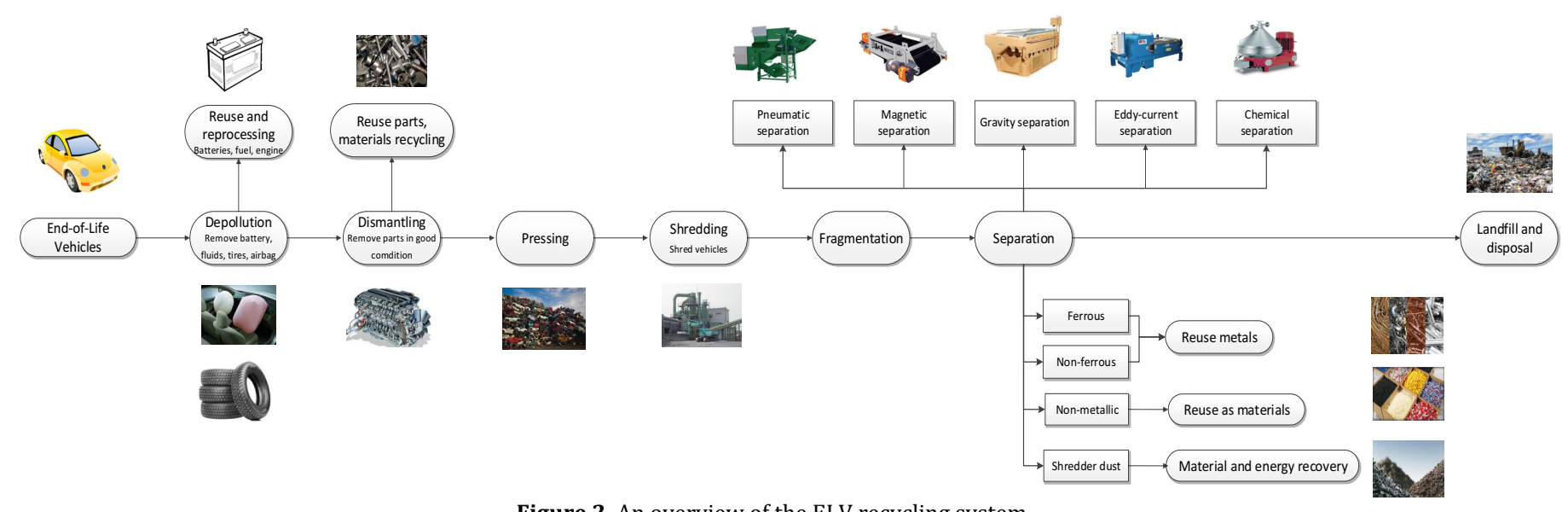

Figure 2. An overview of the ELV recycling system.

\subsection{Potentials in EoL EV recycling}

Similar to the Directive on ELV, regulations and initiatives have also been developed imposing constraints and environmental obligations on E\&E components. To that effect, the EU with its Directives 2002/96/EC (European Commission, 2003a) regarding WEEE and the restriction of the use of certain hazardous substances (RoHS) in E\&E components, respectively, has imposed strict limits. Its strategic target is to increase the recycling of E\&E components products by forcing producers to decrease the content of hazardous materials and to manage their products at the end of their useful life [34].

Article 3 (a) of the WEEE Directive has clarified the criteria for the equipment considered to be covered by Directive 2002/96/EC (WEEE), "Equipment is dependent on electric current or electromagnetic fields in order to work properly, and equipment for the generation, transfer and measurement of such currents and fields." WEEE Directive also states that "This Directive shall apply without the requirement for specific community waste management." Therefore, it should be noted that electronic components like vehicle radios are not covered by the WEEE Directive. If the E\&E component is not specifically designed to be used in a vehicle, that device is covered by the WEEE Directive. But if the device is specially designed with the primary purpose to be used in vehicles, i.e. car radio and CD player, the ELV Directive applies instead [35].

ECUs have been identified to be one of the valuable parts in modern vehicles, both in volume and in the impact on costs. However, the current ELV Directive (based on weighting principles) seems inadequately take into account the management of these types of e-waste [10].

\subsection{Challenges in EV recycling}

This section aims to summarise some of the challenges in current ELV recovery and recycling processes as identified and investigated in this research.

\subsubsection{Reduction of metallic content in contemporary vehicles}

Regarding the profitability of ELV management, existing ELV recycling technologies and processes typically focus on the recovery of metals due to their substantial proportions of existing overall weights. The popularity of electrification in vehicles results in the increase number of E\&E components and therefore SIMs. This trend highlights a need to take the hidden value retrieved from the recovery of PMs and REEs into consideration. In addition, there is a dilemma to strike a balance between achieving performance improvement through light weighting by replacing ferrous and non-ferrous metals with plastics and composites and the improvement of the recyclability of the vehicles at the end of their lives [36].

The lightweight materials, e.g. aluminium and carbon fibre composites, would require more energy to produce and manufacture than conventional materials. The inappropriate treatments of these materials pose risks for both human and the environment. Therefore, this highlights the challenge to gather knowledge of the materials and develop suitable recycling and recovery processes in different cases.

\subsubsection{Lack of component information to facilitate recycling}

The selection of the most appropriate recycling approaches for products is affected by numerous factors, including design construction and material composition [37]. As global data repositories, the International Material Data System (IMDS) and the International Dismantling Information System (IDIS) have been developed and utilised by majority of automotive original equipment manufacturers in the world, aiming at improving data collection and dissemination $[38,39]$. The material information of the products is submitted to the system by the suppliers, and then used by key players in ELV recovery to facilitate meeting the legislative requirements and standards. In the IMDS, automotive electronic devices are simply classified based on their weights distribution, as waste automotive PCBs vary a lot depending on their functionalities [12]. However, the location and the recovery value of the waste PCBs have not been analysed.

The complexity of the material mix and design of the vehicles have been increased significantly. The higher performance and more electronic feature of the E\&E components make it necessary to increase the complexity. It is evident that increased elements contained in the product would make the recycling of it much more difficult. For example, the recycling and recovery of the materials that are present in relatively small quantities would require an elaborate extraction process along with high costs [40]. Therefore, the limited access to the information regarding product design and material composition results in inefficiencies and inconsistencies in the EoL treatment.

\subsubsection{Lack of automation in recycling}

During the course of automotive recycling, manual dismantling and disassembly are expensive and time-consuming. Automated disassembly techniques have been studied in the recycling of WEEE in the format of sensor-based detection [41] and control system using modern simulation technology [42]. Currently in the UK and Europe, there is no automated commercial process available [43], neither in the automotive industry.

One of the principal assumptions within this research is that the most valuable and impactful parts contained in the automotive electronic components are the PCBs; therefore, it is possible to apply the same technological processes for recycling PCBs from EV E\&E 
components as for those from WEEE. In the traditional PCB recycling processes, after the collection and transportation, automotive components would be disassembled and classified into three categories, i.e. steel or aluminium casings, hazardous sub-assemblies, and the PCBs. The metallic casings are sold to the smelters directly as one of the revenue sources and the hazardous parts are dismantled and treated separately. A series of dedicated machines (e.g. shredders, grinders and separators) are utilised to crush the PCBs into uniform powders. It is estimated that $20 \%$ of the powders are lost during the mechanical processes, and $30 \%$ of the powders are metallic materials to be refined and sold as secondary resources [31]. It is identified that the existing automation has been applied in fragmentation and material separation processes in WEEE recycling. In the case of recycling the automotive electronic components, especially for the recovery of PMs and REEs, these techniques are unable to sufficiently liberate complex materials in a cost-effective and energy-efficient manner.

Therefore, it is important to take disassembly into account as a pre-treatment process for future ELV recycling. The disassembly is not only beneficial for remanufacturing, but also to maximise the potential recovery value and avoid the loss of valuable materials contained in the EV E\&E components.

2.3.4 Inability to liberate valuable materials that are present at very low concentrations

Metal recovery is more resource and cost-effective than starting all over again from mining and primary metal production [40]. The recovery of main base metals (i.e. steel, copper and aluminium) has a long tradition, and normally they are contained in simple products. Due to the increase of complexity of multi-material products, metal recycling is becoming a more challenging business.

It is stated that large amount of metals is lost in the recycling chain, caused by inappropriate collection of the EoL products and improper recycling and recovery approaches [4]. Typically, alternative fuel vehicles, such as EVs, need to utilise valuable materials (e.g. PMs and SIMs) for their E\&E components. However, the propositional weight of such valuable materials in the current EVs is still very low. Without proper extraction and recycling approaches, these materials can be easily lost, which provides a new challenge in vehicle recycling as current methods are unable to liberate these valuable materials.

\subsection{Alternative recycling routes for ELVs}

The introduction of complex and advanced material and construction of EV components provides the challenge and the opportunity for future EV recycling and recovery. It highlights a need to develop appropriated recycling techniques and processes that promise the highest material efficiency with lowest overall environmental impacts. Three main different recycling approaches are proposed and discussed in order to understand the material contamination and value recovery from the complex materials included within the EVs, as shown in Figure 3.

The Approach 1 refers to the current vehicle recycling method, including de-polluting the vehicles according to the legislative requirement before dropping them into the shredder, and then using post-shredder technologies to separate materials for recycling and recovery. Metallic materials are normally refined via metallurgical processing.

A dismantling process has been utilised in the Approach 2 where selected valuable components/parts are dismantled and separated from the main stream of the EoL vehicles (e.g. chassis, seats, carpets, low-value plastic components, etc.), and processed these separately. This approach aims at concentrating the targeted materials, and different groups will go through individual shredder streams. For example, E\&E components would be put in a specific waste stream in order to extract and recover specific materials more efficiently.

The purity of the waste stream would determine the possible future qualities and quantities of the recyclate. Therefore, in the Approach 3, the disassembly process can be seen as the extension of the dismantling and separation process. This pre-concentration process aims to break down complex E\&E components into sub-assemblies (e.g. PCBs and magnets) and facilitate the following separation and sorting processes.

With the enhancement of the pre-concentration and avoidance of cross-contamination among the waste streams, approach 3 should achieve improved material yield both in volume and quality. However, more technologies and processes are required. On one hand, difficulties in pursuing the third approach may stimulate more radical innovation and adoption of different design and material choices for ELV systems. On the other hand, the trade-off between increased recyclability and material value recovery requires a comprehensive consideration of the disassembly approach. For example, the third approach results in the highest recovery of PMs and SIMs. When considering the technological and economic feasibilities, the extraction of the negligible amount of valuable material from a complex construction component may not be economically viable or technologically feasible. Therefore, this paper proposes an EoL management framework for EV components recycling that will be further discussed in the following sections.

\section{An Automated Disassembly Approach}

This section provides a more detailed description of the automated robotic disassembly approach in which three specific steps are defined, namely, manual disassembly to assess and develop a comprehensive understanding of product design, initial robotic disassembly to test and examine process capability, and optimisation and validation to improve repeatability and overall efficiency of the robotic disassembly processes (see Figure 4).

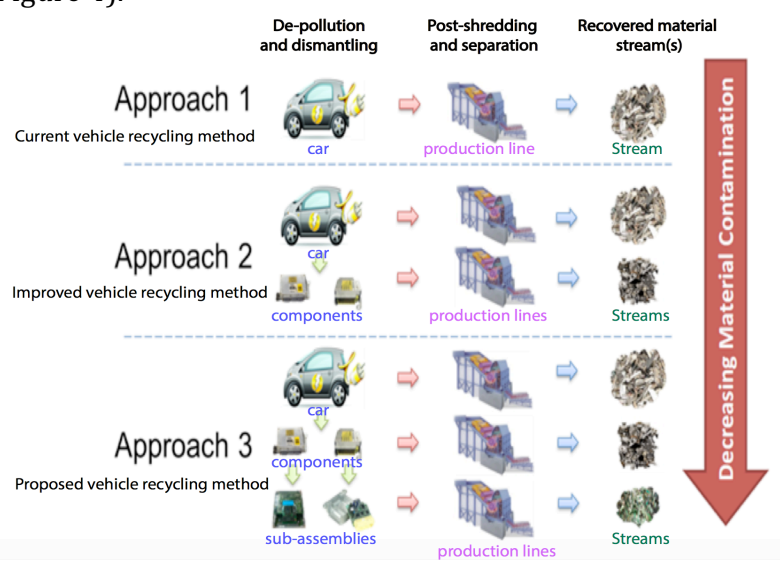

Figure 3. Alternative recycling routes for ELVs. 


\subsection{Step 1: Non-destructive manual complete disassembly}

Prior to proposing and undertaking any EoL strategies for the automotive electronics, there should be a step to characterise the components and their material composition. The characterisation process involves a definition of the parts that are contained in the E\&E components; and a value evaluation of the component by chemical analysis of a sample of them. It allows comprehending the components' material composition for further value classification. The presence or absence of valuable materials closely relates to the potential revenue coming from material recovery.

Furthermore, it has been discussed in the review section that information to facilitate the development of the disassembly strategies is not easily assessable in literature (lacking of existing information about automotive electronic components). Therefore, one of the feasible ways to characterise the automotive electronic components is to implement dedicated laboratory experiments.

This explains the decision to undertake the non-destructive manual complete disassembly at the very first step in the automated disassembly approach. This provides an idea of the potential reachable profitability, by characterising the targeted electronic components. It attempts to identify the characteristics of EV components, addressing questions in the context of the disassembly output, such as:

- How long it takes to achieve full, non-destructive disassembly?

- What are the components' EoL status, design characteristics, and material composition?

- Where are the locations of the targeted parts/materials?

- What is the quantity of the target part/material?

- What tools are used in the manual disassembly processes?

- Is it economical to disassemble a subassembly further to increase material purity?

In order to implement the disassembly approach in a systematic way, there is a need to evaluate the components' recyclability and profitability. To this aim, automotive electronic components will be classified into specific categories based on permutation of their construction and value. The criteria for the classification have been defined with the development of a matrix (see Table 1).

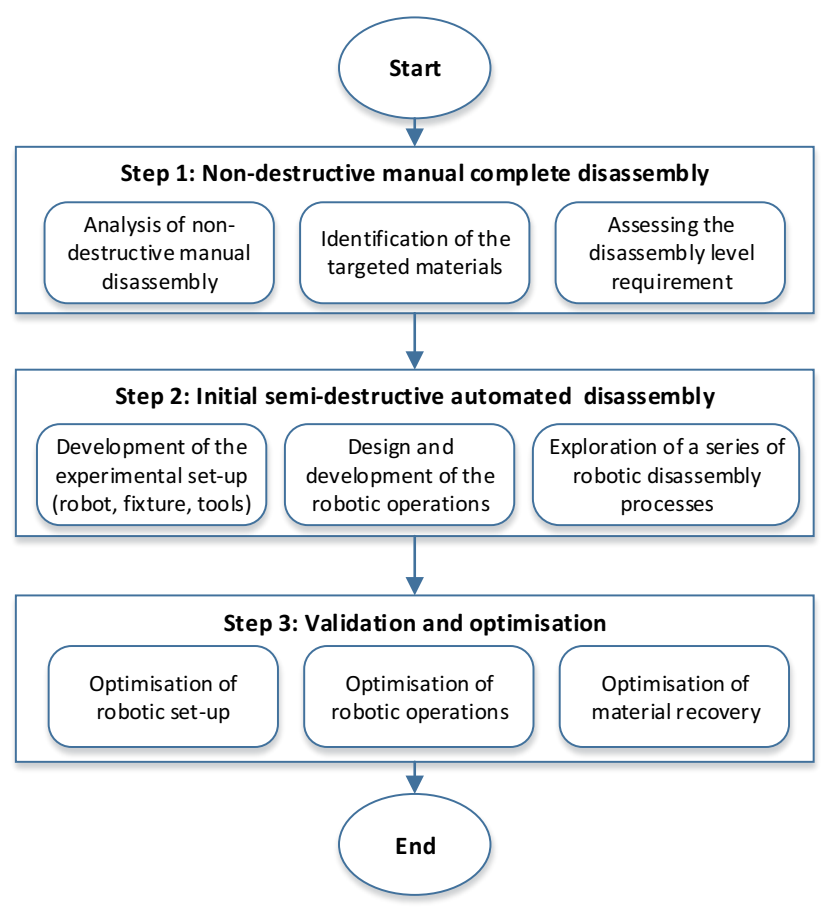

Figure 4. A three-step automated approach for EV recycling.

Table 1. Automotive Electronic Components Classification Criteria.

\begin{tabular}{|c|c|c|}
\hline \multicolumn{3}{|c|}{ Construction } \\
\hline \multicolumn{3}{|c|}{ A. Disassembly Complexity } \\
\hline \multicolumn{3}{|c|}{ A1. Number of parts contained in the component } \\
\hline \multicolumn{3}{|c|}{ A2. Joining methods of the parts } \\
\hline \multicolumn{3}{|c|}{ A3. Disassembly time } \\
\hline \multicolumn{3}{|c|}{ Value } \\
\hline \multicolumn{3}{|c|}{ B. Target Material Concentration } \\
\hline \multicolumn{3}{|c|}{ B1. Concentration of valuable materials (in weight) } \\
\hline \multicolumn{3}{|c|}{ B2. Percentage of valuable materials (in revenue) } \\
\hline \multicolumn{3}{|c|}{ Classification Matrix } \\
\hline Simple, Low & Medium, Low & Complex, Low \\
\hline Simple, Medium & Medium, Medium & Complex, Medium \\
\hline Simple, High & Medium, High & Complex, High \\
\hline
\end{tabular}




\subsection{Step 2: Initial semi-destructive automated robotic disassembly}

Given the feature of the automotive electronic components (the components structure and material composition), the next step is the automated robotic disassembly process.

An assembly process in manufacturing is based on a given type of product for a certain period of time with detailed requirements and instructions. The disassembly process is challenging because it involves a range of different products in the system, and the disassembly process is influenced by the variety of the target components, which therefore creates great uncertainty regarding the configuration of the disassembly system. An initial semi-destructive robotic disassembly process will be developed using a flexible robot cell, in which there is great capacity for the adaptability and flexibility required to ensure the applicability to various components (see Figure 5).

An industrial robot with six degrees of freedom forms the basis of the robotic cell for disassembly processing, with a standard modular fixture and a series of specially designed tools. The specially designed tools are capable of a number of operations, including drilling, cutting, and gripping, using a pneumatic system. The cell is completed with a standard modular worktable, whose purpose is to locate the components with references for high repeatability. However, the fixturing of the components cannot be carried out automatically based on the current set-up.

Based on this set-up, a number of experiments were designed and undertaken to investigate the feasibility of the robotic operations, the capability of the robot tools and the suitability of the fixture platform. The overall objective of this step is to conduct continuous improvement in the robotic disassembly processes. A number of trials were undertaken to investigate the impacts of various factors. Through every trial, there is new learning and a better understanding on the performance of the tools of the fixturing methods.

The following example gives an overview of the exploration of the fixturing method. In the case of the air-bag ECU, as shown in Figure 6, the fixturing Plan A utilised stops and bolts to fix the component on each side. It facilitates the milling process to drill off the screws on the lid from the top to the bottom. However, the component was not forced down towards the table. Alternatively, angle brackets can be used to replace the stops (see Plan B). Clamps are used in fixturing in Plan C and Plan D which takes advantage of the design features of the component. An angle grinder can be used to mill off the screws as one of the proposed disassembly plans, and cut through the lid before gripping the lid and then extracting the PCB inside.

\subsection{Step 3: Validation and optimisation}

This step aims to maximise the value recovery via improvement of the efficiency and repeatability of the robotic disassembly operations. With regard to the fixturing, the required number of component repositionings and time on re-fixturing the component should be minimised. Additionally, the optimal disassembly strategy is generated based on selection of the most suitable tool set up. In order to balance the "trade-off" between level of disassembly and value recovery, the material recovery rate needs to be taken into consideration.

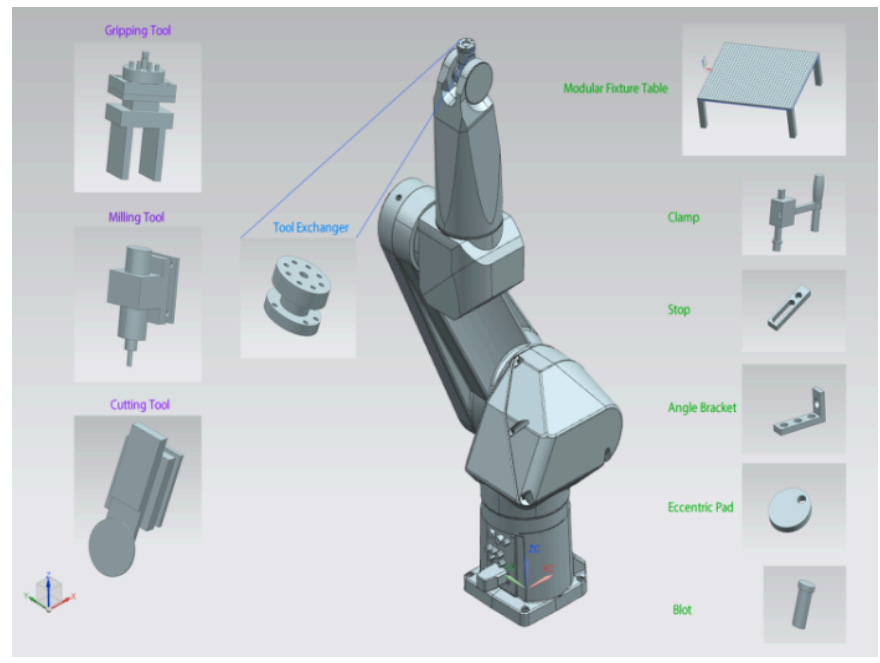

Figure 5. An overview of the robotic cell.

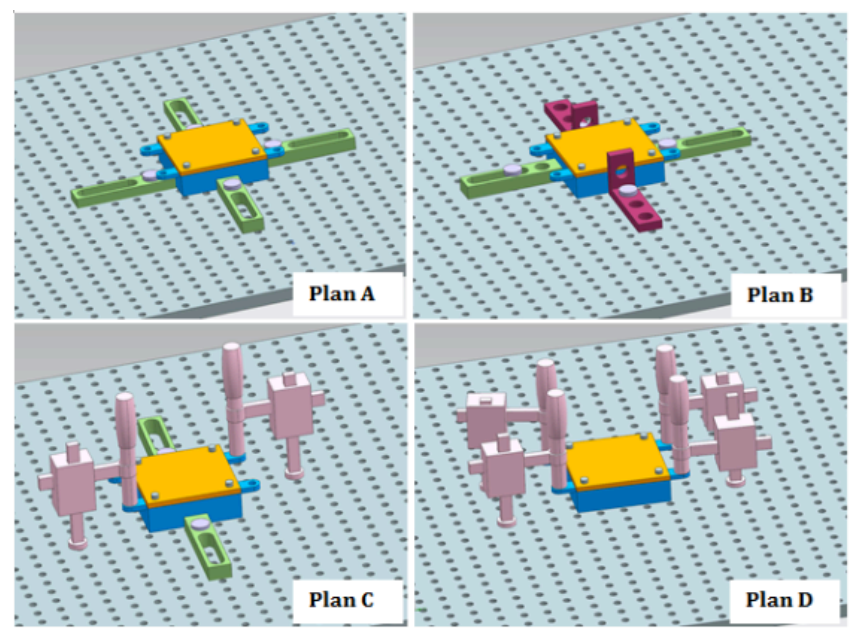

Figure 6. Different fixturing approaches for the air-bag ECU. 


\subsubsection{Optimisation of robotic set-up}

This step aims to minimise the number of part set-ups and tool exchange. It is preferred that the automatic operations can be conducted from one direction without changing the fixture of the component. In addition, it is also beneficial to optimise the sequence of tool use and minimise the tool exchange numbers.

\subsubsection{Optimisation of robotic operations}

The first objective focuses on the optimisation of the operation parameters, including the testing and validation of two major parameters: the overall disassembly time and the reliable and repeatable success rate. The development of optimal disassembly strategies for the EV components also requires the consideration from both economic and technological perspectives.

\subsubsection{Optimisation of material recovery}

The recovery of valuable materials makes, in general, good economic sense. It is noted that a disassembly strategy should be based on the economic validity of the disassembly process and the recovery rate of the materials varies, depending on the technological capability to recover the specific materials. It is identified that the economic value of the disassembly process is associated with a number of variables, such as the complexity of the component itself, the complexity of the fixturing, the numbers of set-up changes required, the number of operations, or the total time to complete disassembly per component. Once a suitable factor has been selected and determined, the indicator of material recovery rate can be quantified, as demonstrated in Equation 1.

$$
\sum \text { Material Removal Rate }\left(\frac{\mathrm{Kg}}{\mathrm{sec}}\right)=\frac{\sum \text { Material }(\mathrm{Kg})}{\text { Time }(\mathrm{Sec})} \quad \text { Equation } 1
$$

A further consideration as to the feasibility of material recovery is that of achievable material yield rates. It is noted that the yield rate for specific materials depends on the recycling and recovery technologies, e.g. the recovery rate for metallic materials, such as steel and aluminium, is higher than the recovery rate of plastic and/or composite materials.

\section{Case study product}

The aim of this section is to demonstrate the applicability of the proposed robotic disassembly approach and analyse its potentials. The selection of the case study component, instead of others, was given by the fact that this electronic device is categorised as a "medium complex, high value" component. The weights of automotive electronic components contained in EVs, based on their functionalities, can vary from 267 grams (air-bag ECU) up to 5586 grams (air conditioner compressor ECU); where the weights of its PCBs range from 0.2 grams (e.g. in door controls or cooling fans) to 784 grams (e.g. navigation or entertainment systems).

The power steering ECU is used to receive torque sensor output and information to judge vehicle conditions and determine the direction and force of the power for the vehicle. Represented in Figure 7, it includes a total number of 9 parts and weighs 759 grams. Table 2 provides the component structure and the parameters that were used to characterise each part: name, subassembly, weight, material composition and reuse value. It also presents an overview of the results of manual disassembly, including the total and individual disassembly time, and operations and tools used during the disassembly.

The non-destructive manual disassembly is used to generate an efficient disassembly sequence to avoid any further operations being necessary for each sub-assembly. The result of the manual disassembly clearly indicated that the valuable parts of the power steering ECU are the casings and PCBs. In order to extract the PCBs from the ECU, the casings have to be removed. Based on the analysis of its material composition and construction, the power steering ECU was classified into the group of "medium complex, high value" electronic components (details of the classification are presented in Table 3).

A variety of factors may impact the automated disassembly process. Therefore, after the targeted parts have been located, a series of automated disassembly processes are designed. The aim of the initial set of experiments is to generate the appropriate automated operations and movements. For example, the kinematics of the robot (i.e. singularity), and the constraints of the tools and fixtures must be taken into consideration. It should be noted that it is a continuous improvement to explore various factors; and in iteration, each factor is tested at least three times. Once the disassembly depth, sequence and movements are generated, automated disassembly is carried out by the robot system in a manual mode that allows the visualisation of the disassembly process and identifies any potential problems. Based on the information gained from the manual disassembly, a series of experimentations were undertaken (i.e. Trial 1 to Trial 6). Different fixturing methods, milling and gripping tools, and associated operating parameters were tested (as shown in Figure 8). The overall disassembly times for each trial are illustrated in Figure 9.

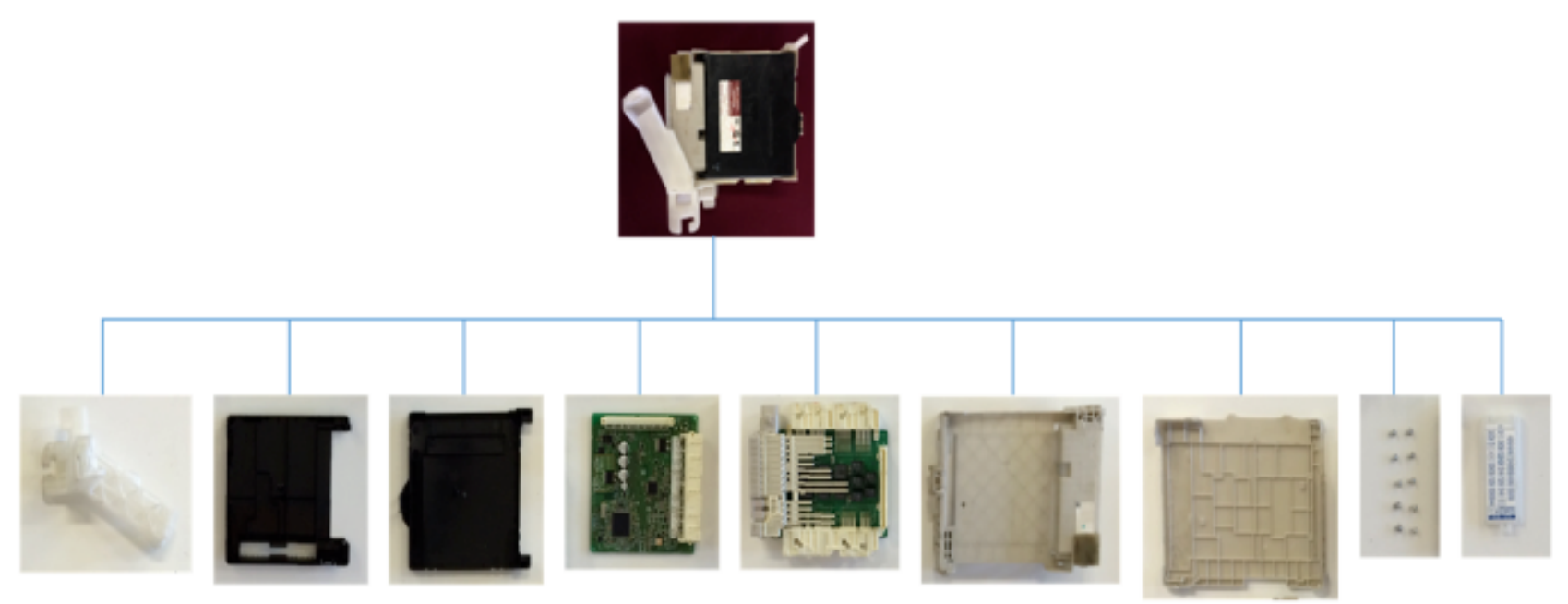

Figure 7. Main sub-assemblies of the power steering ECU (from left to right: bracket, rear black casing, front black casing, $\mathrm{PCB}_{1}$, $\mathrm{PCB}_{2}$, rear white casing, front white casing, screws, and fuse box cover). 
Table 2. Manual disassembly datasheet for power steering ECU.

\begin{tabular}{|c|c|c|c|}
\hline \multicolumn{2}{|c|}{ Name of the components } & \multicolumn{2}{|r|}{ Power Steering ECU } \\
\hline \multicolumn{2}{|c|}{ Total weight (g) } & \multicolumn{2}{|r|}{759} \\
\hline \multicolumn{2}{|c|}{ Total time (minutes) } & \multicolumn{2}{|r|}{8.44} \\
\hline \multicolumn{4}{|c|}{ Weights for each parts (g) } \\
\hline No. & Items & Weight (g) & Material \\
\hline 1 & Brackets & 5 & Multi-materials \\
\hline 2 & Rear black casing & 29 & $\mathrm{PP}$ \\
\hline 3 & Front black casing & 40 & $\mathrm{PP}$ \\
\hline 4 & Printed circuit board $\left(\mathrm{PCB}_{1}\right)$ & 83 & Multi-materials \\
\hline 5 & $\mathrm{PCB}_{2}$ with connectors & 399 & Multi-materials \\
\hline 6 & Rear white casing with clips & 47 & $\mathrm{PP}$ \\
\hline 7 & Front white casing & 141 & PP, nylon \\
\hline 8 & Screws & 9 & Steel \\
\hline 9 & Fuse box cover & 6 & $\mathrm{PP}$ \\
\hline \multicolumn{4}{|c|}{ Manual disassembly processes } \\
\hline No. & Disassembly steps & Time (seconds) & Tools used \\
\hline a & Remove the fuse box cover & 5 & Screwdriver \\
\hline b & $\begin{array}{l}\text { Release the clips on sides to remove } \\
\text { the black box }\end{array}$ & 84 & Pliers \\
\hline c & $\begin{array}{l}\text { Release the clips to get the front cover } \\
\text { of the bottom unit }\end{array}$ & 148 & Pliers \\
\hline $\mathrm{d}$ & Release the clips to open the black box & 17 & Pliers \\
\hline $\mathrm{e}$ & Get $\mathrm{PCB}_{1}$ out of the black box & 40 & Human force \\
\hline f & Get $\mathrm{PCB}_{\mathrm{s}}$ out of the white bottom unit & 113 & Human force \\
\hline g & Unscrew all the screws on $\mathrm{PCB}_{2}$ & 99 & Screwdriver \\
\hline
\end{tabular}

Table 3. Manual disassembly datasheet for power steering ECU.

\begin{tabular}{|l|c|}
\hline Construction & $\begin{array}{c}\text { Case Study Product - } \\
\text { Power Steering ECU }\end{array}$ \\
\hline A. Disassembly Complexity & 9 pieces \\
\hline A1. Number of parts contained in the component & $\begin{array}{c}\text { Mechanical fastening, snap \& } \\
\text { press fits, adhesive bonding }\end{array}$ \\
\hline A2. Joining methods of the parts & 8.44 minutes \\
\hline A3. Disassembly time & \\
\hline Value & $63.50 \%$ \\
\hline B. Target Material Concentration & $88.70 \%$ \\
\hline B1. Concentration of valuable materials (in weight) & \\
\hline B2. Percentage of valuable materials (in revenue) & \\
\hline
\end{tabular}

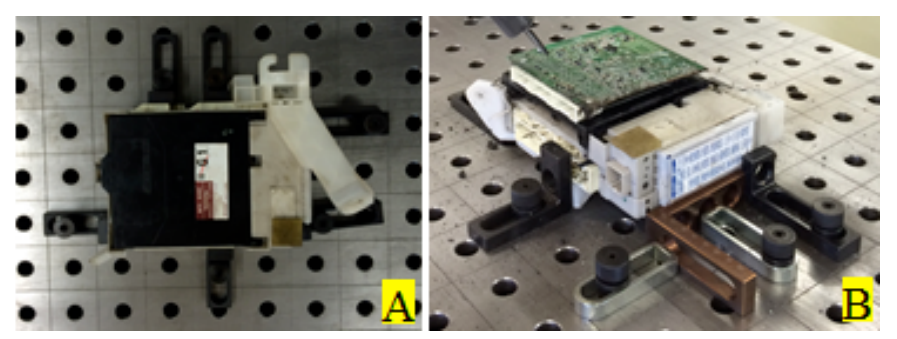

i) Fixture methods of the power steering ECU.

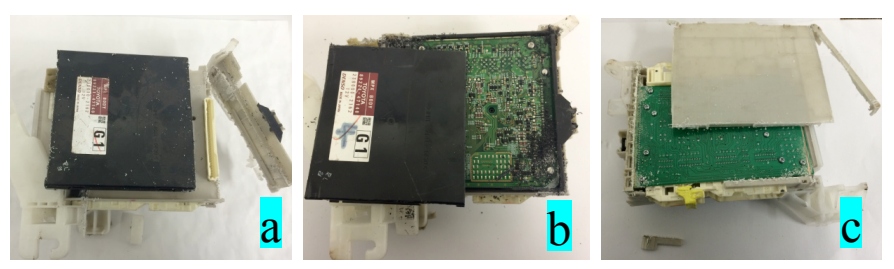

ii) Approaches to get access to the PCBs.

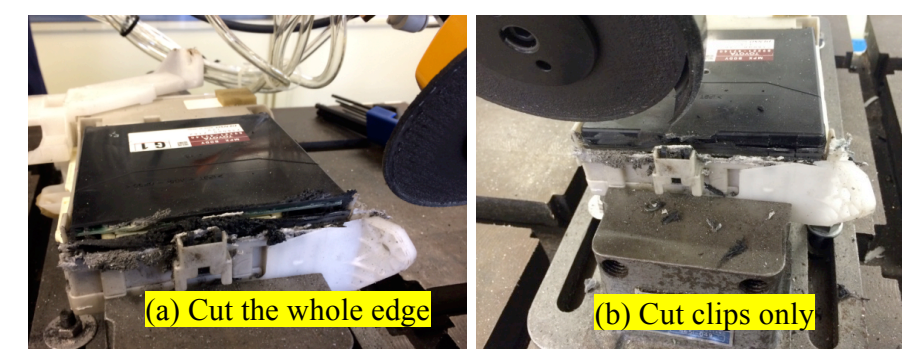



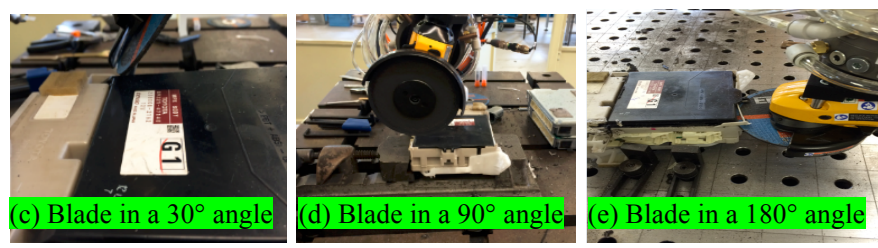

iii) Cutting methods and orientation tests.
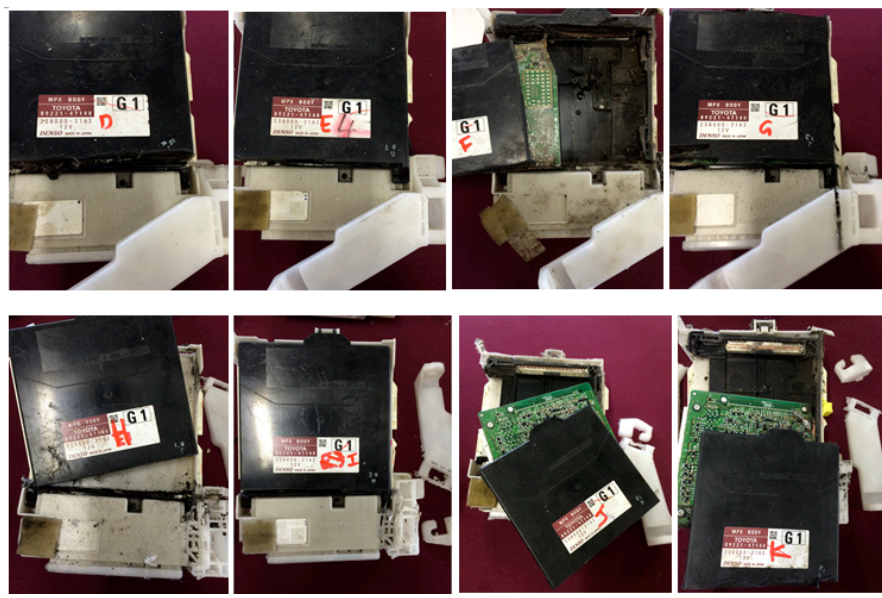

iv) Trials results.

Figure 8. Automated robotic disassembly experiments.

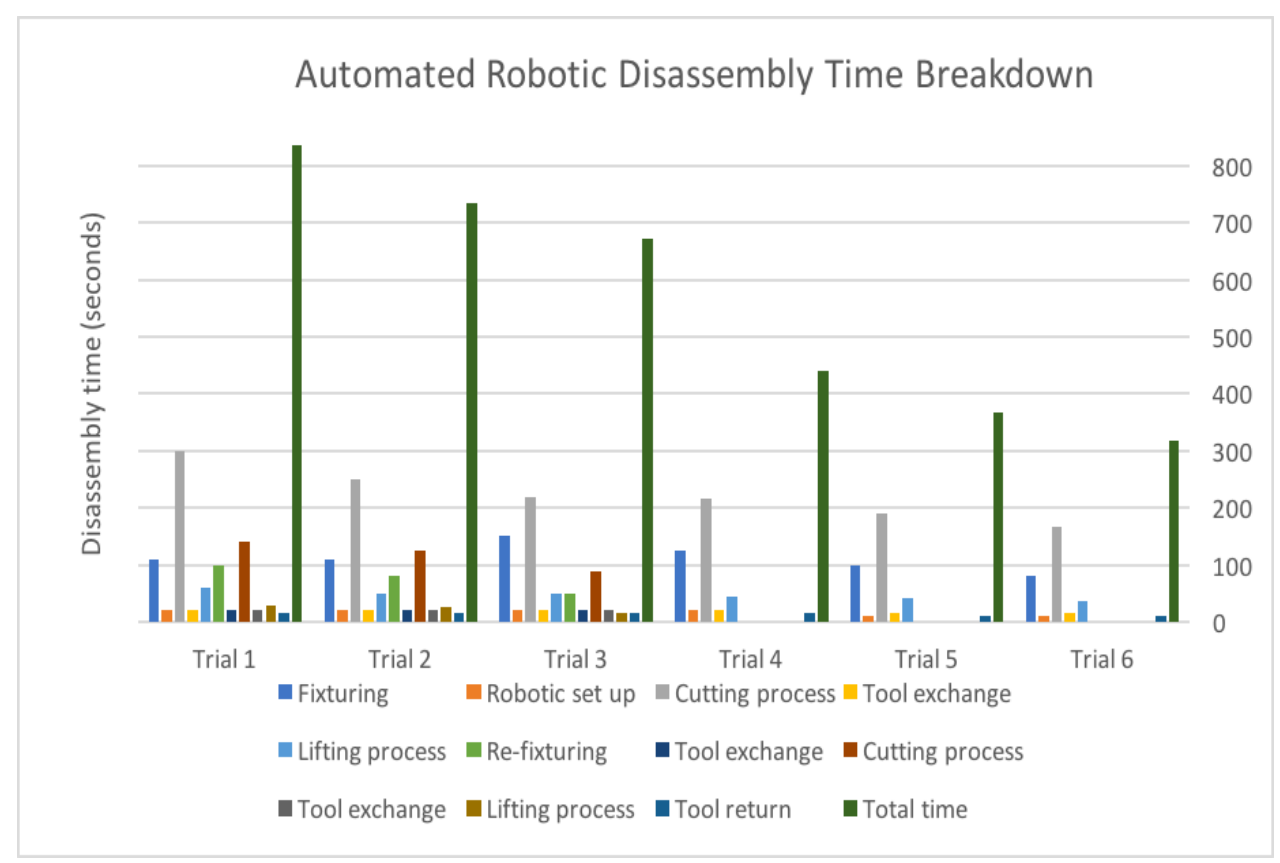

Figure 9. Robotic disassembly result.

In terms of the fixturing approach, Trial 1 and Trial 2 utilised fixture method A which consisted of fewer fixture accessories. Method A was replaced by method B from Trial 3 which provided a higher adaptability for different EoL conditions and design variations of the components. In addition, familiarisation of the operator with the fixturing process gradually contributes to the decrease in fixturing time.

One of the other key findings in these experiments was that the time used in tool change and fixturing processes, in particular during the experiments based on initial robotic process plans, was longer than the subsequent trials'. These times were greatly improved as a result of process optimisation during the consequent experiments. It also highlights the scope for even further improvement in a commercial implementation of such robotic disassembly cells, through more comprehensive customisation of multi-head robotic tools and modular fixture designs. As illustrated in Section 4.3.3, the optimal material recovery rate depends on the value of the recovered materials and the cost of the overall disassembly time. Based on Equation 1, the material removal rates for completed and partial automated disassembly are 0.942 and 1.368, respectively. Therefore, it is evident that for a certain level of disassembly, the majority of the sub-assemblies (PCBs) are extracted with recovery value. Continued disassembly however often just adds cost but with very limited increased revenue. Therefore, the disassembly depth has been further optimised from Trial 4 to Trial 6.

It should be noted that Trial 1 to Trial 5 are used to investigate the feasibility of all robotic disassembly alternatives, regarding the fixturing, tools used, robotic operations and movements; and Trial 6 is the optimal automated robotic disassembly result. As shown in the green bar in Table 3, compared to the previous experiments, the overall robotic disassembly time has been reduced significantly. Thus, the results clearly demonstrate the applicability, feasibility and flexibility of this automated robotic disassembly approach. Based on material analysis of the component sample, it is estimated that more than a $95 \%$ of the materials contained in the automotive electronics can be recovered. 


\section{Conclusions}

ELVs are one of the most important sources of secondary raw materials. The market share of EVs has increased dramatically. The majority of the hidden value contained in EVs is within the E\&E devices in the form of SIMs. However, current vehicle recycling technologies and processes are not able to extract such sensitive, valuable materials that exist in very small quantities. On one hand, this issue provides potential for further research; on the other hand, it points out the limitations impacted due to a lack of readily available data about these materials. Therefore, this highlights a need for developing recycling technologies and processes required for EV components, specially tailored for SIMs recovery.

Recovery of SIMs from end-of-life products needs a series of processes, i.e. mechanical, hydrometallurgical or hydrometallurgical operations. The proposed robotic approach significantly improved the material concentration in the mechanical separation in an efficient way, which facilitated the following chemical or thermal processes (smelting/refining). In this approach, the non-destruction disassembly provided a detailed information of the product that can be used to guide further automated operations, thus the difficulty in data acquisition of the product to be disassembled has been overcome. In addition, the automated disassembly has successfully reduced the operation time and improved the concentration of valuable materials considerably prior to final recycling and refining processes.

Future directions in this research stream are expected to be the application of this approach to a wide range of future vehicles, such as hybrid, full-electric cars and autonomous vehicles. Disassembly automation is promising but needs lots of efforts in the development of relevant techniques to make it more technologically feasible and economically viable, both in developed and developing countries. Additionally, the need to have access to SIMs and PMs has resulted in automotive manufacturers considering involvement in the recycling of E\&E components to ensure the long-term availability of such materials. Therefore, component design improvement, in particular is of paramount importance in supporting future robotic disassembly. Consequently, for the first time, design improvement to aid recycling makes both economic and business sense.

It should also be noted that the fixturing and tools used in this research were designed and developed for current small-scale laboratory experiments. The limitation of their capability highlighted the need for design improvements on fixturing and tools applied to robotic disassembly processes. Hence, bespoke multi-head tools and robotic-based fixtures have significant potentials to be further exploited to facilitate the flexibility and reconfigurability of the robotic disassembly operations and to reduce the overall cost and time of processing. To engage with a diverse amount of product types, it is promising to adopt the concept of cognitive systems and utilising theoretical algorithms for modelling the disassembly processes in the future work of this research to enhance the effectiveness of automated disassembly operations. Market prices for valuable materials could determine critical offsets. Hence, further additional costs needed for a higher recovery rate or automation level can be compensated by the increased value recovery. The flexible robotic cell may be applicable to the treatment of other types of wastes, but their economic performance may vary. Interesting improvements of this work could be the assessment of the sustainability of this automated robotic approach, regarding environmental, technological and economic performance.

\section{References}

[1] Knowles, M. (2013) Through-life management of electric vehicles, 2nd International Through-life Engineering Services Conference, Procedia CIRP, Cranfield University, Cranfield, 5-6 November, 11, 260-265.

[2] Hawkins, T.R., Gausen, O.M. and Strømman, A.H. (2012) Environmental impacts of hybrid and electric vehicles-a review, The International Journal of Life Cycle Assessment, 17(8), 997-1014.

[3] AFDC (Alternative Fuels Data Centre). (2016). Maps and Data: AFV and HEV Model Offerings by Manufacturer. Retrieved from:

http://www.afdc.energy.gov/data/www.afdc.energy.gov/afdc/data/

[4] UNEP. (2011) Recycling Rates of Metals. A Report of the Working Group on Global Metal Flowsto the International Panel for Sustainable Resource

Management. United Nations: Environment Programme.

[5] EUROSTAT. (2014) End-of-life vehicle statistics. Retrieved from: http://ec.europa.eu/eurostat/statistics-explained/index.php/End-of-life vehicle statistics

[6] Environmental Agency. (2014) End of life vehicles (ELVs): guidance for waste sites. Retrieved from: https://www.gov.uk/guidance/end-of-life-vehicles-elvsguidance-for-waste-sites

[7] Sakai, S.I., Yoshida, H., Hiratsuka, J., Vandecasteele, C., Kohlmeyer, R., Rotter, V.S., Passarini, F., Santini, A., Peeler, M., Li, J. and Oh, G.J. (2014) An

international comparative study of end-of-life vehicle (ELV) recycling systems, Journal of Material Cycles and Waste Management, $16(1), 1-20$.

[8] Zorpas, A.A. and Inglezakis, V.J. (2012) Automotive industry challenges in meeting EU 2015 environmental standard, Technology in Society, $34(1), 55-83$.

[9] Chan, C.C. (2007) The state of the art of electric, hybrid, and fuel cell vehicles, Proceedings of the IEEE, 95(4), 704-718.

[10] Cucchiella, F., D’Adamo, I., Rosa, P., and Terzi, S. (2016) Scrap automotive electronics: A mini-review of current management practices, Waste Management

\& Research, 34(1), 3-10.

[11] Kripli J, Vandenberg R, Steinhilper R, et al. (2010) Remanufacturing Automotive Mechatronics \& Electronics - Not a Threat but an Opportunity. APRA Press.

[12] Wang J.J. and Chen M. (2013a) Remanufacturing process for used automotive electronic control components in China, Journal of Remanufacturing, 3(1), 1-

17.

[13] NI. (2009). ECU Designing and Testing using National Instruments Products. National Instruments.

[14] Ardente F, Mathieux F. (2012) Application of the project's methods to three product groups. In: Report No. 2 of the Project Integration of Resource

Efficiency and Waste Management Criteria in European Product Policies-Second phase. European Commission, Joint Research Centre, Institute for Environment and Sustainability.

[15] Smink, C.K. (2007). Vehicle recycling regulations: lessons from Denmark. Journal of Cleaner Production,15(11-12), 1135-1146.

[16] Simic, V. (2013). End-of-life vehicle recycling - a review of the state-of-the-art. Tehnički vjesnik ,20(1), 371-380.

[17] Yi, H.C. and Park, J.W. (2015) Design and implementation of an end-of-life vehicle recycling centre based on loT (Internet of Things) in Korea, Procedia CIRP, Sydney, Australia, 7-9 April, 29, 728-733.

[18] Vermeulen, I., Van Caneghem, J., Block, C., Baeyens, J. and Vandecasteele, C. (2011) Automotive shredder residue (ASR): reviewing its production from endof-life vehicles (ELVs) and its recycling, energy or chemicals' valorization. Journal of Hazardous Materials, $190,8-27$.

[19] ENERGY.GOV (2016). Vehicle technologies office: lightweight materials for cars and trucks. Retrieved from:

http://energy.gov/eere/vehicles/vehicle-technologies-office-lightweight-materials-cars-and-trucks 
[20] Wang, J.J. and Chen, M. (2013b) Technology innovation of used automotive electronic control components recycling in China, Advanced Materials Research, 610, 2346-2349.

[21] Michalos, G., Makris, S., Papakostas, N., Mourtzis, D. and Chryssolouris,G. (2010) Automated assembly technologies review: challenges and outlook for a flexible and adaptive approach, CIRP Journal of Manufacturing Science and Technology, 2(2), 81-91.

[22] Duflou, J.R., Seliger, G., Kara, S., Umeda, Y., Ometto, A. and Willems, B. (2008) Efficiency and feasibility of product disassembly: A case-based study, ClRP Annals-Manufacturing Technology, 57(2), 583-600.

[23] Knoth, R., Hoffmann, M., Kopacek, B., Kopacek P. and Lembacher, C. (2001) Intelligent Disassembly of Electronic Equipment with a Flexible Semi-Automated Disassembly Cell, Proceedings EcoDesign: Second International Symposium on Environmentally Conscious Design and Inverse Manufacturing, 557-561.

[24] Basdere, B. and Seliger, G. (2003) Disassembly factories for electrical and electronic products to recover resources in product and material cycles, Environmental science \& technology, 37(23), 5354-5362.

[25] Vongbunyong, S., Kara, S. and Pagnucco, M. (2013) Application of cognitive robotics in disassembly of products, CIRP Annals-Manufacturing Technology, 62(1), 31-34.

[26] Wegener, K., Andrew, S., Raatz, A., Dröder, K. and Herrmann, C. (2014) Disassembly of Electric Vehicle Batteries Using the Example of the Audi Q5 Hybrid System, Procedia CIRP, 23, 155-160.

[27] Wegener, K., Chen, W.H., Dietrich, F., Dröder, K. and Kara, S. (2015) Robot Assisted Disassembly for the Recycling of Electric Vehicle Batteries, Procedia CIRP, 29, 716-721.

[28] Pintzos,G., Matsas, N., Papakostas, D. and Mourtzis, D. (2016) Disassembly line planning through the of end-of-life handling information from design files, $49^{\text {th }}$ CIRP Conference on Manufacturing Systems (CIRP CMS 2016), Germany, 25-27 May.

[29] Radaschin, A., Filipescu, A., Minzu, V. and Minca, E. (2011) Adaptive disassembly sequence control by using mobile robots and system informant, $15^{\text {th }}$ International Conference on System Theory, Control and Computing, 1-6.

[30] Papakostas, D., Pintzos, N. and Triantfyllou, C. (2015) Computer-aided design assessment of product for end of life separation and material handling. CIRP Annals - Manufacturing Technology, 64(1),185-188.

[31] Feldmann, K., Traunter, S. and Meedt, O. (1999) Innovative disassembly strategies based on flexible partial destructive tools. Annual Reviews in Control, 23, 159-164.

[32] Ferrãoa, P. and Amaral, J. (2006) Assessing the economics of auto recycling activities in relation to European Union Directive on end of life vehicles, Technological forecasting and social change, 73(3), 277-289.

[33] Jody, B., Daniels, E., C.M Duranceau, J. P., and Spangenberger, J. (2010) End-of-Life Vehicle Recycling: State of the Art of Resource Recovery from Shredder Residue, Oak Ridge: Energy Systems Division, Argonne National Laboratory.

[34] Day, C. (2005). Frequently Asked Questions on Directive 2002/95/EC on the Restriction of the Use of certain Hazardous Substances in Electrical and Electronic Equipment (RoHS) and Directive 2002/96/EC on Waste Electrical and Electronic Equipment (WEEE). European Commission: Directorate - General Environment.

[35] Lewis, A.M., Kelly, J.C. and Keoleian, G.A. (2014) Vehicle lightweighting vs. electrification: Life cycle energy and GHG emissions results for diverse powertrain vehicles, Applied Energy, 126, 13-20.

[36] Chiodo, J.D. and ljomah, W.L. (2014) Use of active disassembly technology to improve remanufacturing productivity: automotive application, International Journal of Computer Integrated Manufacturing, 27(4), 361-371.

[37] Zorpas, A.A. and Inglezakis, V.J. (2012) Automotive industry challenges in meeting EU 2015 environmental standard. Technology in Society 34: 55-83.

[38] Cucchiellaa, F., D'Adamoa, I., Rosab, P., \& Terzib, S. (2015). Automotive printed circuit boards recycling: an economic analysis. Journal of Cleaner Production, $1-12$.

[39] Bartl, A. (2014). Moving from recycling to waste prevention: A review of barries and enables. Waste Management \& Research, 32(9), 3-18.

[40] UNEP. (2013) Metal Recycling: Opportunities, Limits, Infrastructure. United Nations: Environment Programme.

[41] Weigl-Seitz, A., Hohm, K., Seitz, M. and Tolle, H., 2006. On strategies and solutions for automated disassembly of electronic devices. The International Journal of Advanced Manufacturing Technology, 30(5-6), 561-573.

[42] Kim, H.J., Kernbaum, S. and Seliger, G., 2009. Emulation-based control of a disassembly system for LCD monitors. The International Journal of Advanced Manufacturing Technology, 40(3-4), 383-392.

[43] Cryan, J., Freegard, K., Morrish, L. and Myles, N., 2010. Demonstration of flat panel display recycling technologies. WRAP project. 